\title{
Infrastructure and Testing Needs for Molten Salt Reactor Safeguards
}

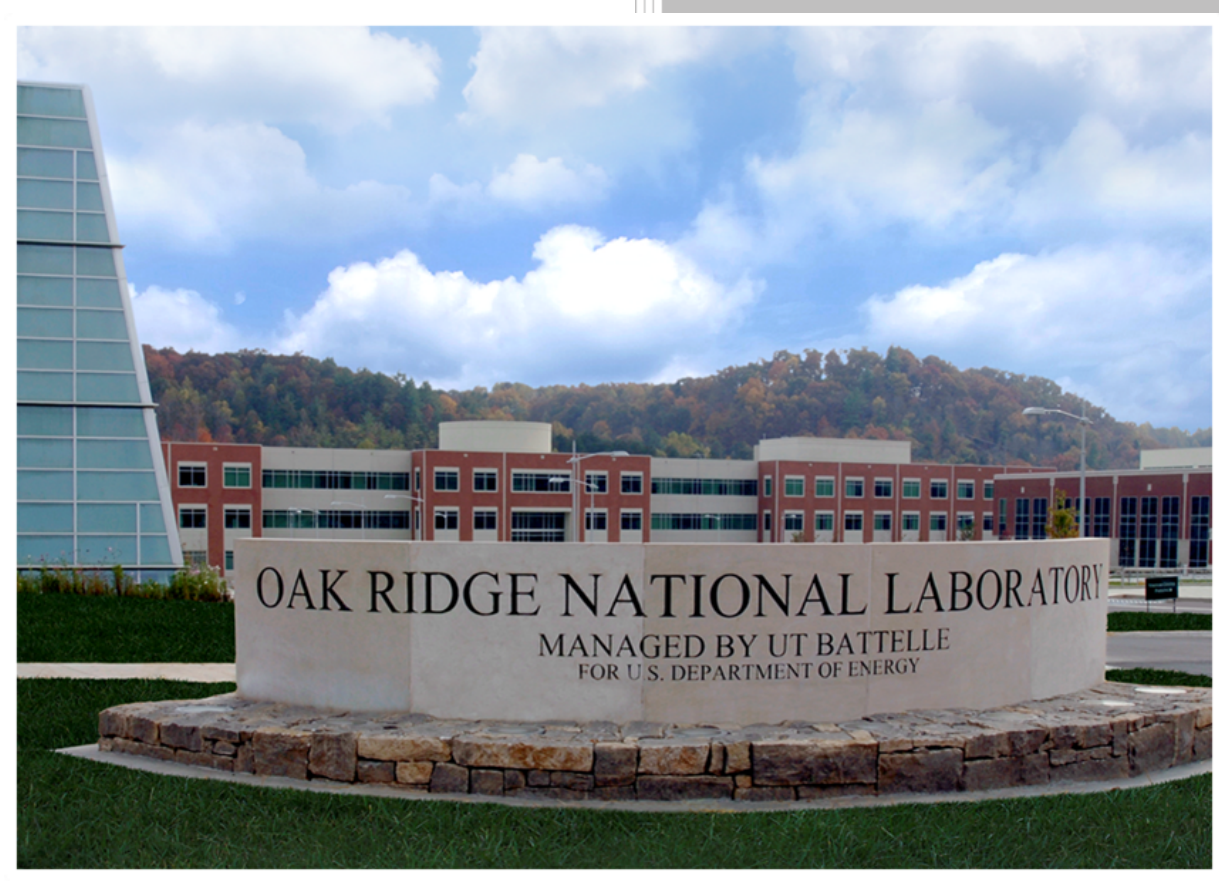

Logan M. Scott Michael P. Dion Karen K. Hogue Sean E. O'Brien Greg T. Westphal

March 2021

Approved for public release. Distribution is unlimited. 


\title{
DOCUMENT AVAILABILITY
}

Reports produced after January 1, 1996, are generally available free via US Department of Energy (DOE) SciTech Connect.

Website www.osti.gov

Reports produced before January 1, 1996, may be purchased by members of the public from the following source:

\author{
National Technical Information Service \\ 5285 Port Royal Road \\ Springfield, VA 22161 \\ Telephone 703-605-6000 (1-800-553-6847) \\ TDD 703-487-4639 \\ Fax 703-605-6900 \\ E-mail info@ntis.gov \\ Website http://classic.ntis.gov/
}

Reports are available to DOE employees, DOE contractors, Energy Technology Data Exchange representatives, and International Nuclear Information System representatives from the following source:

Office of Scientific and Technical Information

PO Box 62

Oak Ridge, TN 37831

Telephone 865-576-8401

Fax 865-576-5728

E-mail reports@osti.gov

Website http://www.osti.gov/contact.html

This report was prepared as an account of work sponsored by an agency of the United States Government. Neither the United States Government nor any agency thereof, nor any of their employees, makes any warranty, express or implied, or assumes any legal liability or responsibility for the accuracy, completeness, or usefulness of any information, apparatus, product, or process disclosed, or represents that its use would not infringe privately owned rights. Reference herein to any specific commercial product, process, or service by trade name, trademark, manufacturer, or otherwise, does not necessarily constitute or imply its endorsement, recommendation, or favoring by the United States Government or any agency thereof. The views and opinions of authors expressed herein do not necessarily state or reflect those of the United States Government or any agency thereof. 
Nuclear Nonproliferation Division

\title{
INFRASTRUCTURE AND TESTING NEEDS FOR MOLTEN SALT REACTOR SAFEGUARDS
}

\author{
Logan M. Scott \\ Michael P. Dion \\ Karen K. Hogue \\ Sean E. O'Brien \\ Greg T. Westphal
}

March 2021

Prepared by

OAK RIDGE NATIONAL LABORATORY

Oak Ridge, TN 37831-6283

managed by

UT-BATTELLE, LLC

for the

US DEPARTMENT OF ENERGY

under contract DE-AC05-00OR22725 



\section{CONTENTS}

ABSTRACT (...

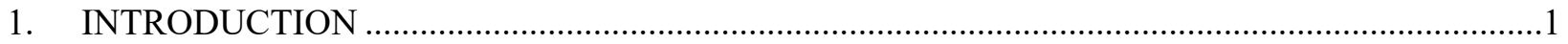

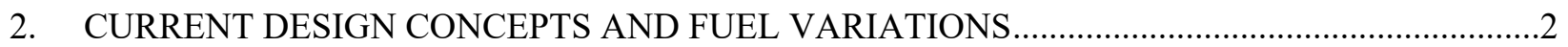

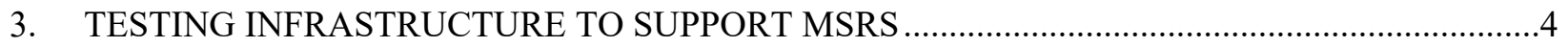

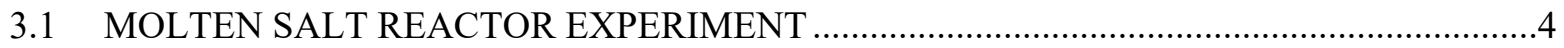

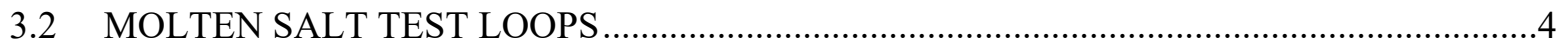

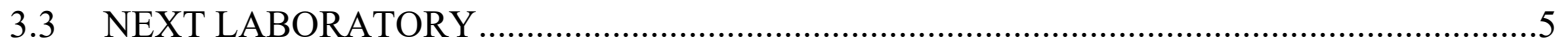

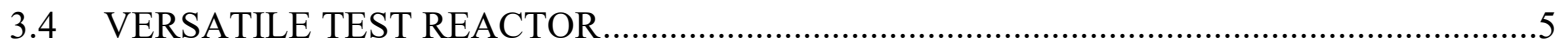

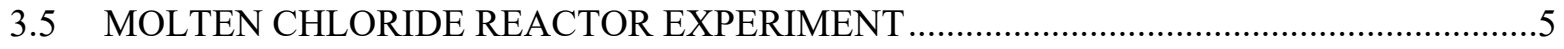

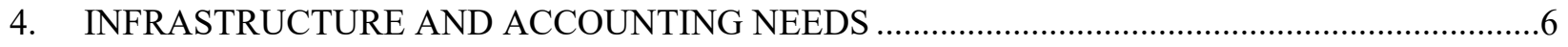

4.1 ONLINE MONITORING OF FRESH FUEL ADDITIONS ...........................................

4.2 MATERIAL ACCOUNTANCY DURING MAINTENANCE OR SHUTDOWN ...................7

4.3 RESIDUAL HOLDUP ON EFFLUENT COMPONENTS ...................................................

4.4 MEASUREMENTS OF IRRADIATED SALT OUTSIDE OF THE REACTOR

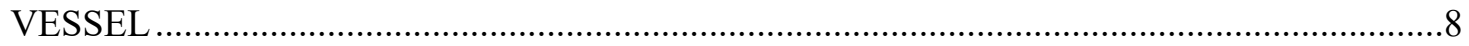

4.5 ROBUST INSTRUMENTATION FOR FUEL MONITORING AND HANDLING ................8

4.6 ADVANCED MODELING AND SIMULATION CAPABILITIES …...............................9

4.7 WASTE FUEL SALT HANDLING, STORAGE, AND MEASUREMENT ….......................10

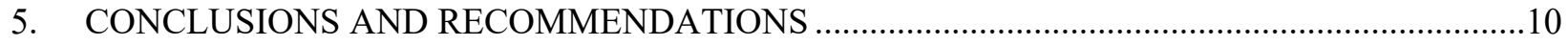

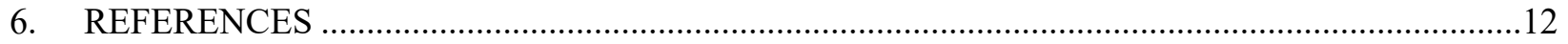




\begin{abstract}
Molten salt reactors (MSRs) are an attractive advanced reactor technology because of their increased fuel utilization and efficiency, the ease of fueling, and the potential to use alternative fuel cycles, including thorium and breeder/burner scenarios. Since an MSR has never been domestically operated for commercial electricity production, minimal infrastructure exists to support performance and materials testing, reactor licensing (including research, test, and operating reactors), and technology development in general. These factors could present challenges for the commercialization of the proposed design technology. Several research and development efforts and investments have begun to identify and supplement the infrastructure to accommodate the molten salt concept, including the United States Department of Energy Office of Nuclear Energy Molten Salt Reactor Program. This report reviews safeguards technology and domestic infrastructure to support the evaluation of nuclear safeguards (primarily material control and accounting) measures and approaches for salt-fueled MSRs.

Recommendations for potential priority infrastructure investments, including safeguards measurement test beds and future research, are presented.
\end{abstract}

\title{
1. INTRODUCTION
}

Recently, MSRs have garnered more interest as a potential advanced nuclear power reactor design and received substantial research and development investment. The United States Department of Energy (DOE) has shown its continued commitment to the MSR community recently and announced the selection of two MSR concepts under the Risk Reduction for Future Demonstration ${ }^{1}$ program. The two molten salt projects are a fluoride salt-cooled design (Kairos Power LLC) and a fast spectrum molten salt-fueled design (Southern Company Services Inc.). MSRs are characterized by molten salts within the reactor system for fueling or cooling purposes. The use of a molten salt may allow for increased passive safety measures and minimize downtime for (re)fueling ${ }^{2}$. The molten salts, usually halide salt compounds (historically fluoride based), can serve as the primary medium for the fuel, as the coolant circuit, or both.

Based on the fuel characteristics and the primary use of the molten salt, the majority of MSR design concepts can be classified into two groups:

- Salt-cooled reactors: A solid non-salt fuel undergoes fission and is cooled by a separate, non-fueled primary salt system.

- Salt-fueled reactors: A flowing salt containing fissile or fertile fuel material that fissions when in the core and flows throughout the primary system serves as both a fuel and a coolant.

The unique nature of MSR concepts and design variations has resulted in the breadth of MSR designs currently under development ${ }^{3}$. However, the technological infrastructure needed to support the material control and accountancy (MC\&A) aspect of domestic safeguards research and development efforts for these designs is limited in the United States. This report identifies areas where current fuel salt measurement capabilities, monitoring technologies, and material testing infrastructure can be developed or improved to support effective and efficient MC\&A program development for MSRs. Effective

\footnotetext{
${ }^{1}$ https://www.energy.gov/ne/articles/energy-department-s-advanced-reactor-demonstration-program-awards-30million-initial

${ }^{2}$ https://www.energy.gov/ne/articles/southern-company-and-terrapower-prep-testing-molten-saltreactor\#: : :text=MCFR $\% 20$ Benefits\&text=If $\% 20$ there $\% 20$ is $\% 20 \mathrm{a} \% 20$ loss, Other $\% 20$ benefits $\% 20$ include $\% 3$ A\&text =Ability $\% 20$ to $\% 20$ use $\% 20$ multiple $\% 20$ fuels,uranium $\% 2 \mathrm{C} \% 20$ or $\% 20$ even $\% 20$ spent $\% 20$ fuel

${ }^{3}$ https://aris.iaea.org/sites/MSR.html
} 
accounting for nuclear material is a pre-requisite for both domestic licensing and international deployment where international nuclear safeguards would likely be applied.

\section{CURRENT DESIGN CONCEPTS AND FUEL VARIATIONS}

Proposed MSR designs employ a variety of fuel and salt combinations, and each would require a unique set of operational and processing design characteristics. Commercial light water reactors (LWRs) traditionally use low enriched $(<5 \%){ }^{235} \mathrm{U}$ as fuel and all US commercial reactors have an open (or oncethrough) fuel cycle, with no actinide separations (i.e., reprocessing) from the irradiated fuel. Burner-type salt-fueled MSRs are being developed by multiple commercial entities, with the intention of operating with a conventional uranium-plutonium fuel cycle. Some developers are designing reactors that use high assay low enriched uranium (HALEU), similar to other advanced reactor designs, whereas others are designing reactor concepts that primarily use plutonium as fuel.

Some MSR designs aim to optimize the ${ }^{232} \mathrm{Th}-{ }^{233} \mathrm{U}$ fuel cycle by breeding fissile ${ }^{233} \mathrm{U}$. Distinct from commercial LWRs in the United States, many MSR designs include plans for either on-site or off-site separation of actinides, such that the fissile material can be recycled and reused as fuel in the MSR. Compared to LWRs, which all operate within a thermal neutron energy spectrum, MSR concepts have been proposed to operate within a thermal neutron energy spectrum, a fast neutron energy spectrum, or may even shift between fast and thermal energies through large reactivity changes during operation (i.e., spectral shift). All liquid-fueled MSRs will require online refueling to maintain criticality.

Finally, the salt matrix becomes important from a thermal, chemical, and neutronic standpoint. The salt must have the proper chemical characteristics so that the fuel and the fission products are soluble, corrosivity of the structural components is limited, and its constituent isotopes are insensitive to neutron and/or gamma irradiation. Historic MSR designs, like those operated at Oak Ridge National Laboratory (ORNL) in the $1960 \mathrm{~s}$, used fluoride salts (e.g., lithium fluoride [LiF] and beryllium fluoride $\left[\mathrm{BeF}_{2}\right]$ ). To maintain reactivity, the lithium was enriched to a high purity of ${ }^{7} \mathrm{Li}$, specifically FLiBe salt, to reduce neutron capture reactions on the ${ }^{6} \mathrm{Li}$ isotope (notably, this capture reaction is also the source of ${ }^{3} \mathrm{H}$ production). Some modern MSR designs, particularly fast spectrum concepts, propose using molten chloride salts. Chlorine has two stable isotopes, ${ }^{35} \mathrm{Cl}$ and ${ }^{37} \mathrm{Cl}$, and neutron-induced reactions with ${ }^{35} \mathrm{Cl}$ can produce sulfur and pose a concern of corrosion during operation. Therefore, isotope separation processes to enrich chlorine to the heavier ${ }^{37} \mathrm{Cl}$ are warranted and this has become technologically and economically feasible, prompting commercial entities to pursue fast-spectrum ${ }^{238} \mathrm{U} / 239 \mathrm{Pu}$ breeder reactors with ${ }^{37} \mathrm{Cl}$ salts.

With the high variance in design characteristics, it is initially beneficial to group potential designs by key reactor characteristics. Figure 1 shows the current design features and attributes of salt-fueled MSRs. 


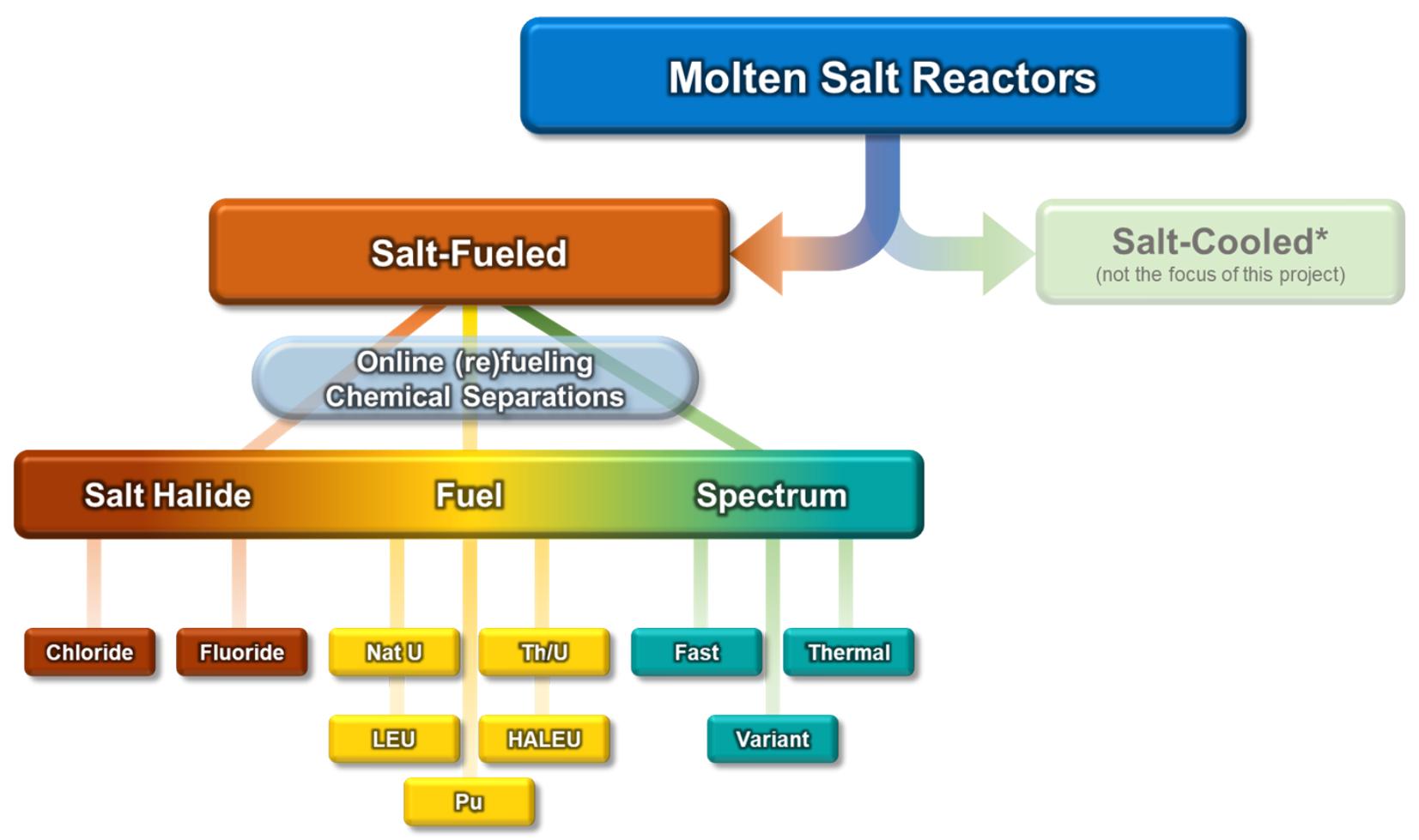

Figure 1. Main design characteristics of MSRs. This figure presents the numerous combinations of attributes that can vary per design.

Based on guidance from the Office of Nuclear Materials Safety and Safeguards (NMSS) at the US Nuclear Regulatory Commission and the MC\&A challenges that are inherent to liquid-fueled MSRs (Hogue et al. 2021), the focus of this infrastructure needs assessment will be on salt-fueled reactors. It should be noted that salt-cooled reactor designs will also face new challenges from a MC\&A perspective. The control and accountancy measures for existing designs will likely be similar to those associated with salt-cooled pebble bed reactors. For these existing reactor designs, the salts, or inert gases, act solely as the coolant, and the MC\&A issues will likely pertain to the fuel in the form of TRi-structural ISOtropic (TRISO) spheres or fuel compacts. High-level guidance and recommendations for material accountancy in these reactor systems have been previously detailed (Kovacik, Gibbs, and Scott 2020).

For salt-fueled reactors, mixing the fissile fuel with the coolant in a single, continuous, fuel salt flow loop (or two loops, as in the case of some of the breeder MSR designs) presents unique challenges that will require novel MC\&A solutions for any MSR developer seeking deployment in the United States. From a baseline concept, these reactors will utilize special nuclear material (SNM), in a manner that may be more analogous to reprocessing facilities than traditional reactors because of the integration of a radiological material into a fluid flowing medium. This is a primary concern because licensing explicitly requires MC\&A plans for facilities that contain SNM, which includes plutonium, ${ }^{233} \mathrm{U}$, or uranium enriched in the isotopes ${ }^{233} \mathrm{U}$ or ${ }^{235} \mathrm{U}$, but does not include source material, as defined by Title I of the Atomic Energy Act of 1954. However, because the purpose of MSRs is power generation from SNM fuel, they will require an MC\&A approach and measures that are suitable for advanced reactors that use online fueling, such as PBRs. Currently, the NRC does not have regulations or guidance that covers non-LWR/advanced reactors, specifically as they apply to a dynamic fuel. These factors provide the framework for the infrastructure gap analysis. 


\section{TESTING INFRASTRUCTURE TO SUPPORT MSRS}

The current testing infrastructure in the United States for molten salt reactors is relatively sparse. Experiments on fuel salt matrices were performed in the past; however, as of 2020, there are no actively operational test reactors that are either salt-fueled or salt-cooled. Much of the current testing infrastructure pertinent to molten salts exists in forced- or convection-driven loops that investigate the salt chemistry and its effect on material corrosion in the absence of fissile material. However, many projects are currently underway that would allow for new tests of salt-fuel and the interaction of such salts with reactor components. Some projects may allow for systems-level experiments of a model salt-fueled reactor. The following sections describe the historical, existing, and planned testing infrastructure.

\subsection{MOLTEN SALT REACTOR EXPERIMENT}

The Molten Salt Reactor Experiment (MSRE) achieved criticality in June 1965 and was mostly operational until its final shutdown in December 1969. The MSRE allowed numerous important contributions that can be used as reference and guidance for current MSR design planning. While it is not current experimental infrastructure, a collection of around 600 reports present reference data including the plant design plans, refueling operations, monitoring equipment, corrosion studies, fission product solubility, and off-gas treatment among other topics. Although not commercial scale, the MSRE demonstrated the ability to sustain a fission reaction using a graphite-moderated core with a fluoridebased salt-fueled primary loop and a salt-cooled primary cooling circuit. The implications of this experiment are optimistic and provide a significant starting point for research and development activities needed for modern MSR designers, as well as research related to MC\&A approaches for MSRs.

\subsection{MOLTEN SALT TEST LOOPS}

Many test loops have been constructed to investigate the behavior of molten salt compounds. These loops operate solely with molten salt and without the addition of fissile or fertile material or fission products. Early convection- and pump-driven loops were constructed at ORNL in the 1960s to study corrosion chemistry of fluoride salts (Crowley, McDonald, and Clark 1963). However, after the conclusion of the MSRE testing campaign, experimentation on molten salts halted, and technology development continued to support LWRs.

As a renewed interest in advanced reactor designs emerged in the early $2000 \mathrm{~s}$, many of the dormant salt flow loops were revived, and new loops were developed. ORNL used thermal convection-driven loops with FLiBe salts to investigate corrosion at high temperatures caused by interactions between the molten salt and component alloys (Raiman and Lee 2018). Additionally, other liquid salt loops were constructed at ORNL to test other fluoride-based salts, such as the FLiNaK ( $\mathrm{LiF}-\mathrm{NaF}-\mathrm{KF}$ ) salt in the liquid salt test loop. A small-scale instrumentation test loop is being developed at Argonne National Laboratory to test various safeguards sensors and other instrumentation. This Modular Flow Instrumentation Testbed (MFIT) will be pressurized to linearly transfer molten salt from one vessel to another and provide extensive ports for installation and testing sensors. Forced flow loops, or molten salt test loops that utilize pumps to drive flow, have also been developed by several entities, such as Nuclear Engineering eXperimental Testing (NEXT) Laboratory, ${ }_{4}^{4}$ Copenhagen Atomics, ${ }^{5}$ and ORNL (Aaron et al. 2015). These forced flow loops will provide a more robust testing platform for molten salt characteristics moving forward.

\footnotetext{
${ }^{4}$ https://www.acunextlab.org/about

5 https://www.copenhagenatomics.com/pdf/Loop 5.1_ Datasheet.pdf
} 
Outside of direct nuclear applications, several large-scale molten salt test loops exist, with the most prominent application being in the consolidated solar power and battery storage technologies. Texas A\&M University has acquired a large-scale molten chloride salt flow loop previously owned by Shell Oil that will primarily be used to test hermetic insulating bladders. ${ }^{6}$ Sandia National Laboratories operates the molten salt test loop that uses molten nitrate salts to investigate thermal storage capacity (Gill, Kolb, and Briggs 2013). Finally, ORNL, in collaboration with Argonne National Laboratory, is developing a facility for chloride salts for testing of components and corrosion control methods (Robb et al. 2019). Although these facilities do not have a direct mission to support MSRs, they demonstrate test beds that will investigate salt chemistry and instrumentation longevity that can be leveraged for nuclear power molten salt applications.

\subsection{NEXT LABORATORY}

The NEXT Laboratory is a molten salt test reactor under development in Abilene, Texas, by the NEXTRA university partnership that includes Abilene Christian University, Texas A\&M University, University of Texas at Austin, and Georgia Institute of Technology. This project aims to construct a series of molten salt related test campaigns to evaluate the performance of various materials and components. By the end of 2020, two molten salt flow loops were constructed. One smaller convection-driven loop is used for salt chemistry characterization, and a second larger loop allows for reactor components testing ${ }^{4}$.

Additionally, the partnership is pursuing licensing for the Molten Salt Research Reactor ${ }^{3}$ that would be a full-scale salt-fueled reactor specifically for research purposes. With similarities to the MSRE, the Molten Salt Research Reactor is designed to be low power with a large thermal capacity, allowing for systemslevel testing of reactor components during operation. Its primary salt would be a uranium/fluorine-based fuel salt $\left(\mathrm{LiF}-\mathrm{BeF}_{2}-\mathrm{UF}_{4}\right)$ matrix, operating with $\mathrm{HALEU}\left(19.5 \%\right.$ enriched in $\left.{ }^{235} \mathrm{U}\right)$. The reactor is expected to be constructed by 2030 .

\subsection{VERSATILE TEST REACTOR}

The Versatile Test Reactor (VTR) is a concept intended solely for the testing of advanced nuclear fuels, components, and instrumentation. With a proposed location at the Idaho National Laboratory test site, the VTR would be a user-driven facility that could be used to support necessary MSR research and development, such as fuel salts and instrumentation focused experiments. While the VTR is not specifically being developed for MSR applications, it will have the capability of testing various advanced fuels, including fuel salts, and the various test ports included in the design could provide a location to experiment with potential testing safeguards technology. With more than 30 university, industry, and national laboratory partners, the VTR is still in the concept development and design phase. This phase is expected to conclude in 2023, and construction will take 3-5 years, making the VTR fully operational between 2026 and 2028.

\subsection{MOLTEN CHLORIDE REACTOR EXPERIMENT}

Southern Company and TerraPower have received US DOE funding to develop a molten chloride fast test reactor. Their concept will be a scaled-down version of a commercial reactor that uses a chloride-based salt-fueled design called the Molten Chloride Reactor Experiment (MCRE). It is designed to be fuel flexible, allowing for varying levels of uranium enrichment. In addition to acting as the demonstration reactor for the TerraPower design, the MCRE currently aims to validate reactor thermal hydraulics and safety analysis codes using the reactor concept. However, it may provide a location for testing of

${ }^{6}$ https://indico.cern.ch/event/564485/contributions/2398371/attachments/1410060/2156360/Molten_Salt_Technolog y_.pdf 
chloride-based fuel salts under reactor operating conditions in the future. The partnership plans to target operations for the reactor in the late 2020s.

\section{INFRASTRUCTURE AND ACCOUNTING NEEDS}

Current MC\&A technology, concepts, and approaches, will require evaluation and potential future development to support the large variation in MSR fuel cycles and reactor technologies (Worrall et al. 2018). Therefore, to develop methodologies that adapt current MC\&A approaches, the dynamic nature of MSR fuel cycles must be investigated. The fissile and fertile material concentrations will constantly change because of online refueling, burnup of the fissile material, ingrowth of fissile material from any fertile isotopes, and any removal of fission products or volatile gases via chemical or mechanical separations. In addition, the effects of both normal and off-normal reactor operating parameters on quantities of nuclear material and resulting signatures for monitoring need to be understood to support the development of an effective MC\&A program. This research will require both modeling and simulation of various reactor concepts, as well as experiments to validate simulation results. Other research efforts should intentionally focus on accounting for SNM during routine maintenance, startup, and shutdown periods in addition to normal (equilibrium) operations. Changes in chemical, physical, and isotopic composition, as well as proposed operational practices such as frequency of refueling, chemical separations, and draining the system for maintenance, will differ for each of the MSR designs, and the measurement requirements and MC\&A approaches will have to accommodate these MSR varieties. The infrastructure needed to further develop safeguards approaches and technologies are discussed based on their categorical application and use.

\subsection{ONLINE MONITORING OF FRESH FUEL ADDITIONS}

Because of the dynamic nature of the MSR fuel salt, online fuel monitoring may be critical to quantify the amount of fissile material and other actinides present in the reactor system at specified points of interest. However, most designs have self-contained primary loops for the fuel salt. This allows material balance boundaries to potentially be set between key systems in the primary loop; thus, the reactor vessel and other system components may be viewed as individual accountancy volumes. This does not necessarily mean that each of these volumes need be defined as a formal material balance area or even separate inventory control areas. However, considering this approach would allow the operator and the MC\&A program at the facility flexibility in designing the most effective program to meet defined US Nuclear Regulatory Commission requirements. To maintain an accurate material accountancy of these volumes, the quantities and characteristics of the input to each volume or across each boundary must be known. For example, if a reactor vessel is the defined boundary, measuring the SNM in fresh fuel salt, monitoring any additions of fresh fuel, and measuring and monitoring the SNM in any irradiated salt leaving the system could potentially improve modelling and burnup calculations for the reactor itself used for material accountancy.

Quantifying SNM in fresh fuel could be done by a variety of known testing methodologies, such as assaying fresh fuel or taking in situ measurements during fuel addition. Use of Raman spectroscopy techniques, which use a combination of inelastic scattering and vibrational state measurements, have been demonstrated to differentiate the chemical compositions of various salts, ${ }^{7}$ and other investigations have shown the characteristic differences between compounded uranium concentrates (Ho et al. 2015). These capabilities could be coupled with similar SNM monitoring technologies in enrichment facilities. While it is uncertain whether the existing systems would be directly applicable, measurement systems could be developed that use principles applied in existing technologies, such as the Unattended Cylinder

7https://www.energy.gov/sites/prod/files/2019/04/f61/CSP\%20Summit2019\%20Sporian\%20Harsh\%20SaltRamenS pec 0.pdf 
Verification Station, and modified or adapted to measure isotopic concentrations for fuel-salt (Smith et al. 2016). These efforts would also require modeling of fresh fuel additions to the reactor vessel, with simulations for various levels of fuel burnup. Additionally, any onsite fuel salt synthesis would have to be explored along with methods to characterize fuel salt components as they arrive at the reactor, how they are manipulated and mixed, and how they are introduced into the fuel stream.

\subsection{MATERIAL ACCOUNTANCY DURING MAINTENANCE OR SHUTDOWN}

One important MC\&A question with a salt-fueled design is how to account for SNM during maintenance and shutdown periods. During such periods, irradiated fuel salt may be drained from portions of the system and stored in containers; however, some of the fuel salt will remain as residue (i.e., holdup) in the drained components and may require different material accountancy measures than those used during routine operations to quantify the SNM present (especially if any of these components are removed from the reactor site during maintenance and refurbishment activities). Unirradiated salt may be used to flush the system, in which case SNM in the waste flush salt would need to be accounted for. These quantities will be needed to effectively evaluate any potential inventory difference (ID).

Some MSR designers have incorporated methods of redirecting fuel salt flow to other parallel pathways to ensure continued reactor operations during maintenance periods. However, the fuel salt drained from the components under maintenance will need to be quantified to ensure no material is unaccounted for during these periods. Although many existing test loops can be used to investigate how salt components and fission products plate out or remain in certain locations in equipment as holdup during normal reactor operations, additional research efforts must be made to understand how SNM quantities can be most effectively and efficiently measured and quantified during periods of maintenance or shutdown specific to MSRs. An MC\&A program for an operational MSR will need to incorporate specific plans to inventory SNM during these maintenance periods. Simulations and modeling of equipment could determine the most appropriate methods of measuring residual material, and testing using surrogate materials in salt can be used to establish standards and methods for accounting of SNM during these periods. Future investments in experimental measurements using convection or forced-flow test loops would provide necessary information to understand SNM and fuel-salt behavior critical to MSR operations.

\subsection{RESIDUAL HOLDUP ON EFFLUENT COMPONENTS}

Additional infrastructure investments will be needed to investigate how specific reactor system components contribute to the total system SNM holdup, and thus holdup quantification and associated uncertainty. As stated previously, many of these components will have to undergo routine maintenance because of the corrosive nature of molten salts. Some other components, such as filters, are designed to induce holdup and will have to be replaced regularly. Past measurements on deposition on MSR components indicated that fission product deposition varies by component, but there is little or no past experimentation for SNM quantities for system component holdup (Houtzeel and Dyer 1972). Waste components will have to be stored on-site for a period of time because of the high radioactivity from the presence of any residual fission products.

Based on the size and scale of the equipment, the physical and chemical properties of the salt and the equipment, and the degradation of the material's surface because of corrosion at the planned time of replacement, it is possible that notable quantities of SNM may still remain in equipment, even after flushing the system. Further research is needed to determine estimated quantities of SNM that may remain as residual material. If large enough, these quantities could potentially contribute to a significant ID if not quantified directly, or the quantities could introduce uncertainties that are outside of what the US Nuclear Regulatory Commission deems acceptable for MSRs based on future regulatory requirements and 
guidance. These quantities will eventually impact security requirements, and they will be used in any shipper-receiver records should the components be shipped off-site.

Many of the procedures and infrastructure investments that needed to support development of effective and efficient quantification of SNM in drained fuel salt would also support quantification of SNM in effluent components. Effective methods for containment and surveillance are needed to ensure potential SNM holdup in these components is not modified as it is stored and before internal or external reprocessing. Modeling and simulation capabilities are needed to develop estimated baseline quantities of material holdup in different component types based on operational parameters, identify appropriate cool down times before further measurements and/or decontamination efforts, which will dictate the necessary time needed for containment and surveillance measures.

\subsection{MEASUREMENTS OF IRRADIATED SALT OUTSIDE OF THE REACTOR VESSEL}

Routinely monitoring fuel salt after it leaves the reactor vessel through a sampling protocol could provide useful fuel burnup and isotopic data. Sampling was performed during operation of the MSRE, and measurements were performed on $10 \mathrm{~g}$ samples of fuel salt to determine chemical and isotopic information (Gallaher 1971). In addition to holdup in system components, safeguards concerns could arise from fuel salt interactions with components like the primary heat exchange systems or with systems that remove fission product gases from the fuel salt. Because the same fluid matrix that produces fission is also used as the primary heat transfer medium, secondary measurement points may be necessary at other reactor system components that induce chemical or physical changes to the fuel salt. These systems cause the fuel salt to undergo either chemical or physical changes that must be monitored to ensure accurate SNM quantification. This could involve measurement systems similar to ones that monitor fuel inserted into and discharged from the reactor vessel, but it may require novel equipment designs depending on the specific system equipment being monitored.

Investments will have to be made for modeling and simulation of fuel salt interactions with non-reactor vessel components. Specifically, the models must be developed for any system that removes fuel salt or fission product gasses from the system, and these models must demonstrate the effects that any removal has on SNM quantities recirculated into the reactor vessel to ensure, for example, that SNM is not unintentionally diverted into a different process stream. Additional testing should monitor how temperature changes or fuel salt composition changes induced by secondary reactor systems affect the ability to accurately measure SNM quantities entering and leaving such systems. Recommendations to address this gap and provide empirical data are to invest in molten salt irradiations containing expected concentrations of fuel material. Starting with bulk material irradiations (i.e., not molten) would provide baseline data. Subsequent experiments would consider instrumentation to heat the salt prior to irradiation and performing NDA measurements to provide potential data of radioactive emission signatures.

\subsection{ROBUST INSTRUMENTATION FOR FUEL MONITORING AND HANDLING}

Direct access to irradiated fuel salt will likely be limited because of the extremely high radiative dose, making SNM accounting difficult. If the current neutron and gamma NDA measurement systems used in industry are applied to MSRs, instrument accuracy, longevity, and overall reliability are expected to diminish when compared with their current applications. Additionally, it is still unknown whether online fuel monitoring will be able to use in situ NDA systems, or if the SNM quantification will have to be done for a batch sample through a parallel measurement line, such as a process line with a smaller diameter and some separation from the reactor vessel to reduce activity. Some combination of these two systems may be used for operational accountancy of SNM in irradiated fuel salt. In situations containing

off gas fission product removals, the potential to characterize fuel concentrations from the fission product decay signatures is unknown. Establishing and investing in test loops containing fissile and fertile 
material with neutron induced fission product generation is recommended to understand the sensitivity of these measurements, particularly in off gas processing components.

Research at the Los Alamos National Laboratory (LANL) under a parallel Advanced Reactor Safeguards project are evaluating nondestructive assay (NDA) technologies for application to MSR safeguards needs. The goals of this LANL-led project are to measure and evaluate (gamma-ray and neutron) signatures from samples similar to material at an MSR facility, assess limits of rapid anomaly detection and characterization of material compositions, and evaluate the NDA concepts for the high-radiation environments likely applicable to in situ MSR measurements (Croce et al. 2020). This instrumentation is currently being installed at the VTR in the testing laboratory to be used in future campaigns and experiments. Additional research at the Pacific Northwest National Laboratory is pursuing optical spectroscopy methods for online measurements to support MSR development. The R\&D combines the use of Raman and UV-Vis techniques to provide dentification and quantification, oxidation state, and molecular and elemental species present in the molten salt. The equipment has been tested on various chloride based salts and oxidation states of $\mathrm{U}$ and $\mathrm{Pu}$.

Infrastructure investments will be needed to assess the necessary improvements to measurement equipment to ensure instrument accuracy and longevity for fuel salt monitoring. This will require modeling and simulation of the radiation fields from irradiated fuel salts and their effects on materials used in current monitoring instruments. Actual experimentation with irradiated fuel salts and measured exposure to instrument components could validate such simulations and provide insight about unforeseen challenges with associated SNM measurements. Alterations could require redesigning of existing systems, increased strengthening of component shielding, or further integration of high-fidelity networking components.

\subsection{ADVANCED MODELING AND SIMULATION CAPABILITIES}

Computer code packages are used to evaluate the safety of a fuel cycle including consequence management, radiation shielding, burnup and depletion, and prediction of radionuclide inventories. However, these codes are maintained and applied against current LWR technology. The proposed advanced reactor designs include various advanced fuel types, enrichments, and fuel cycles. Because of the variance in fuel salt characteristics, it will be necessary to develop modeling and simulation capabilities that allow assessments of key signatures for MSR MC\&A safeguards.

Strategies for the development and modifications to existing code packages, including SCALE (Wieselquist, Lefebvre, and Jessee 2020), are underway to evaluate and characterize the non-LWR activities. These codes are extremely useful for criticality safety and overall fuel cycle analysis and can be used to support safeguards and MC\&A for fixed-fuel applications. However, the fluid nature of saltfueled MSRs has required modifications to SCALE (Betzler, Powers, and Worrall 2017) and prompted new tool development, TRANSFORM (Michael S. Greenwood 2018). TRANSFORM is a system-level modeling tool that allows for dynamic inventory tracking of specified fission products as a function of reactor operating conditions. These new tools and capabilities are being used to support MC\&A safeguards efforts and understand potential indicators and correlations during the fuel cycle (Dion et al. 2020), and further development could couple fuel depletion with system-level flow models to examine key measurement points in a MSR model for isotopic accounting purposes. Other examples are sensitivity and statistical analysis of the MSR fuel cycle using SCALE (Higgins, Shoman, and Cipiti 2021), and using the dynamic simulations to model process monitoring measurements for evaluation in a safeguards approach. In addition, dynamic modeling tools have been used to investigate various operational features of fuel evolution during burnup and will leverage frequency response as an indication of potential SNM diversion (Singh et al. 2018; Singh et al. 2020). 
Additionally, for MC\&A signature characterization, the fuel salt chemistry for each design may cause complications for signature acquisition and accuracy, especially in designs with proposed fuel processing. Radiation signatures will be different for each design and based on fuel utilization, limiting the broad use of these signatures to correlate how much fissile material is being created for material measurement methods. To better understand the needs for measurement system designs, research will be performed to investigate the coupling between the fuel salt chemistry and the system neutronics behaviors. This means developing models that investigate how chemical changes in the salt components affect the chemistry and neutronic of the fissile material and fission products. Preliminary results for initial dynamics assessments show promise (Nguyen et al. 2021); however, a more robust understanding of the coupled system would more accurately indicate quantities of SNM and source material, allowing for higher assurance against theft or diversion from a system. Therefore, the verification of models and simulations via testing is crucial to the advancement of the understating of fuel salt behavior during irradiation and the methods that could be used to measure and predict the production and utilization of fissile material and the total quantities of SNM present in an MSR reactor system and its components.

\subsection{WASTE FUEL SALT HANDLING, STORAGE, AND MEASUREMENT}

Waste streams and components are important considerations for MSR developers as well as from an MC\&A planning perspective. Because the reactor system relies on a constantly flowing coolant-fuel matrix, the fission products, some actinides, and gasses will be contained within this matrix until separated into various waste streams, similar to conditions demonstrated in the MSRE. Design characteristics of MSRs vary by developer, but each reactor will generally have the following waste streams: pure salt and separated salt streams; off-gas streams for fission gasses; organic-based waste streams; metallic-based waste streams; and operational and decommissioning waste streams (Riley et al. 2019). From an initial materials accountancy perspective, each of these feeds will need to be monitored to confirm the presence or absence of nuclear materials. This may require some testing and infrastructure investment considerations previously expressed for effluent components and equipment integrity.

Some reactor designs rely on salt waste streams that require some sort of processing to separate the nuclear material from the salt and other waste components, with constant monitoring of the nuclear materials before and after separation. Baseline testing for many separation techniques have been performed for chloride-based salts, but not as many studies have been conducted for fluoride salts (Riley et al. 2019). Additionally, other reactor designers, such as Flibe Energy, are proposing operating with an

online processing system that intentionally separates protactinium 233 online into decay tanks to produce U233, which is then recycled into the reactor system. Therefore, monitoring systems would be necessary to ensure that waste from the reactor system remains intact during on-site storage.

\section{CONCLUSIONS AND RECOMMENDATIONS}

Although significant strides are being made to meet the experimental test bed and infrastructure needs for MSR development, this report details the gaps in such programs that will still need to be addressed to fully support evaluations of MC\&A for MSRs and thus where future priority R\&D investments could be made. Several of the ongoing projects show promise to meet some of these needs, but there are still areas where technical capabilities need to be expanded in a way that support MSR developers with the tools to ensure accurate material accounting and controls of SNM within their respective designs. The recommended priority areas for $R \& D$ investment in infrastructure and accounting needs, are provided in these three cross-cutting categories: 1) conducting irradiated salt experiments and accessing representative nuclear material forms/types, 2) developing online or in situ monitoring capabilities, and 3) expanding system components testing to consider nuclear material accounting. 
Many of the currently operating test facilities for molten salts focus on the salt chemistry and material corrosion properties. However, none of these facilities are actively investigating irradiated salt mixtures, let alone salts with fissile components. With no experiments on irradiated salts since the 1960s, there is a significant knowledge gap for how these fuel salts will behave, in addition to the effect of this behavior on the relevant signatures of nuclear material within these fuel-salts, which greatly hinders the development of effective monitoring and measurement techniques for safeguards purposes. Modeling and simulation of salt-fueled reactor systems can provide a (renewed) baseline understanding of how flowing fuel behaves in a reactor system, but these capabilities need to be expanded for the various proposed fuel cycles. Testing of irradiated salts will provide some validation to these models and direction about how to increase model fidelity for various MSR designs. Additionally, these tests would provide insight about design parameters of fuel monitoring systems, as well as how robust these instruments must be to withstand the thermal, chemical, and radiological stresses imposed by the irradiated fuel salts. Once the tests are concluded, methods would have to be developed and implemented to ensure knowledge and understanding of the quantities and locations of all SNM, which provides opportunities to test various containment and surveillance technologies.

Additionally, online monitoring techniques and instrumentation are needed to provide accurate fuel accounting at various points in the reactor system and corresponding fuel cycle. Because of the variance in MSR designs and operating conditions, it may be difficult to find a single measurement system or method that fits each design equally, thus prompting the need for test beds for the application of existing, modified, or new technologies. In situ monitoring techniques similar to those implemented at reprocessing facilities, especially pyroprocessing, may provide a technological basis. However, they would need to be modified or expanded using targeted NDA techniques, possibly ones analogous to the rapid anomaly detection or concepts for the high-radiation environments currently under development at LANL. Also, a measurable indication of where chemical and physical changes occur in the reactor system is necessary so that those locales can be monitored. Advanced modeling and simulation capabilities could provide a baseline for coupling between fuel salt chemistry and reactor neutronics, and dynamic fuel salt simulations could provide isotopic quantities that are integrated into detector response models for signature characterization at various points. This could provide critical insight into the radiation field and its effect on detector functionality and indicate necessary shielding measures for monitoring instruments. Combining all of these efforts would allow for effective material accountancy during operations and allow conclusions to be drawn about how this can be used to draw material balances, early identification of diversion of SNM and to maintain such an accountancy during periods of shutdown or maintenance. Where feasible, it is recommended to test existing or newly developed prototypical safeguards technologies in parallel to the testing of system components using the planned salt loops, experiments, and facilities.

Finally, additional testing is needed on system components from a material accounting perspective. Many components are going to experience some degree of material holdup during normal operations, and the concern about holdup is expounded by the need for frequent maintenance of these components. Models that demonstrate the effects of component corrosion and system holdup need to be integrated, and these models could be used to simulate the holdup of SNM for any variety of effluent components replaced during maintenance. However, testing on such components will be needed to validate these models. These tests would allow the opportunity to measure the amount of residual SNM in the components and determine the necessary MC\&A procedures for any decommissioning process. Even if the residual material is minimal, accounting measures should be able to determine the quantities of SNM present and ensure that all pertinent MC\&A regulations are followed. 


\section{REFERENCES}

Aaron, Adam M., Richard Burns Cunningham, David L. Fugate, David Eugene Holcomb, Roger A. Kisner, Fred J. Peretz, Kevin R. Robb, Dane F. Wilson, and Jr Yoder, Graydon L. 2015. "High Temperature Fluoride Salt Test Loop." In, Medium: ED; Size: 92 p.: ; Oak Ridge National Lab. (ORNL), Oak Ridge, TN (United States).

Betzler, B. R., J. J. Powers, and A. Worrall. 2017. 'Molten salt reactor neutronics and fuel cycle modeling and simulation with SCALE', Annals of Nuclear Energy, 101: 489-503.

Croce, Mark, Katrina Koehler, Krystel DeCastro, David Mercer, Sophie Weidenbenner, Matthew Carpenter, Duc Vo, Daniela Henzlova, and Howard Menlove. 2020. "Experimental Validation of Nondestructive Assay Capabilities for MSR Safeguards." In.

Crowley, J. L., W. B. McDonald, and D. L. Clark. 1963. "Design and Operation of Forced-Circulation Corrosion Testing Loops with Molten Salt." In.

Dion, Michael P., Louise G. Worrall, Stephen Croft, and Logan Scott. 2020. "Molten Salt Reactor Signatures and Modeling Study " In.: Oak Ridge National Laboratory.

Gallaher, R. B. 1971. "Operation of the Sampler-Enricher in the Molten Salt Reactor Experiment." In.

Gill, David Dennis, William J. Kolb, and Ronald J. Briggs. 2013. "An evaluation of pressure and flow measurement in the Molten Salt Test Loop (MSTL) system." In, Medium: ED; Size: 24 p.: ; Sandia National Lab. (SNL-NM), Albuquerque, NM (United States).

Higgins, Michael, Nathan Shoman, and Benjamin Cipiti. 2021. "Limitations of MUF for MSRs." In INMM 2021.

Ho, D. M. L., A. E. Jones, J. Y. Goulermas, P. Turner, Z. Varga, L. Fongaro, T. Fanghanel, and K. Mayer. 2015. 'Raman spectroscopy of uranium compounds and the use of multivariate analysis for visualization and classification', Forensic Science International, 251: 61-68.

Hogue, Karen, Philip Gibbs, Michael P. Dion, and Mike Poore. 2021. "Domestic Safeguards Material Control and Accountancy Considerations for Molten Salt Reactors." In.: Oak Ridge National Laboratory.

Houtzeel, A., and F. F. Dyer. 1972. "STUDY OF FISSION PRODUCTS IN THE MOLTEN-SALT REACTOR EXPERIMENT BY GAMMA SPECTROMETRY." In, 213. Oak Ridge National Laboratory.

Kovacik, D., P. Gibbs, and L. Scott. 2020. "MC\&A Program Performance Assessments for Pebble Bed Reactors." In.: Oak Ridge National Laboratory.

Michael S. Greenwood, Benjamin Betzler, Lou Qualls. 2018. "Dynamic Systems Models for Informing Licensing and Safeguards Investigations of Molten Salt Reactors." In.: Oak Ridge National Laboratory.

Nguyen, Manh-Thuong, Vassiliki-Alexandra Glezakou, Jason Lonergan, Bruce McNamara, Patricia D. Paviet, and Roger Rousseau. 2021. 'Ab initio molecular dynamics assessment of thermodynamic and transport properties in $(\mathrm{K}, \mathrm{Li}) \mathrm{Cl}$ and $(\mathrm{K}, \mathrm{Na}) \mathrm{Cl}$ molten salt mixtures', Journal of Molecular Liquids, 326: 115262.

Raiman, S. S., and S. Lee. 2018. 'Aggregation and data analysis of corrosion studies in molten chloride and fluoride salts', Journal of Nuclear Materials, 511: 523-35.

Riley, B. J., J. McFarlane, G. D. DelCul, J. D. Vienna, C. I. Contescu, and C. W. Forsberg. 2019. 'Molten salt reactor waste and effluent management strategies: A review', Nuclear Engineering and Design, 345: 94-109.

Robb, Kevin R., Padhraic L. Mulligan, Graydon L. Yoder Jr., Kurt Smith, and Jordan Massengale. 2019. "Facility to Alleviate Salt Technology Risks (FASTR): Preliminary Design Report with Failure Modes and Effects Analysis." In, Medium: ED; Size: 63 p.: ; Oak Ridge National Lab. (ORNL), Oak Ridge, TN (United States). 
Singh, V., M. R. Lish, A. M. Wheeler, O. Chvala, and B. R. Upadhyaya. 2018. 'Dynamic Modeling and Performance Analysis of a Two-Fluid Molten-Salt Breeder Reactor System', Nuclear Technology, 202: $15-38$.

Singh, V., A. M. Wheeler, B. R. Upadhyaya, O. Chvala, and M. S. Greenwood. 2020. 'Plant-level dynamic modeling of a commercial-scale molten salt reactor system', Nuclear Engineering and Design, 360.

Smith, Leon E., Karen A. Miller, James R. Garner, Sean Branney, Benjamin S. McDonald, Jennifer B. Webster, Mital A. Zalavadia, Lindsay C. Todd, Jonathan A. Kulisek, Heather Nordquist, Nikhil S. Deshmukh, and Scott Stewart. 2016. "Viability Study for an Unattended UF6 Cylinder Verification Station: Phase I Final Report." In.

Wieselquist, W. A., R. A. Lefebvre, and M. A. Jessee. 2020. "SCALE Code System." In. ORNL: ORNL. Worrall, Andrew, Benjamin R. Betzler, George Flanagan, David Eugene Holcomb, Jianwei Hu, Donald N. Kovacic, A L. Qualls, and Louise G. Worrall. 2018. "Molten Salt Reactors and Associated Safeguards Challenges and Opportunities." In IAEA Safeguards Symposium. 